Portland State University

PDXScholar

Civil and Environmental Engineering Faculty

Publications and Presentations

Civil and Environmental Engineering

4-2017

\title{
Remote Measurements of Tides and River Slope Using an Airborne Lidar Instrument
}

\author{
Austin S. Hudson \\ Portland State University, hudsona@pdx.edu \\ Stefan A. Talke \\ Portland State University, talke@pdx.edu \\ Ruth Branch \\ University of Washington - Seattle Campus \\ Chris Chickadel \\ University of Washington - Seattle Campus \\ Gordon Farquharson \\ University of Washington - Seattle Campus
}

See next page for additional authors

Follow this and additional works at: https://pdxscholar.library.pdx.edu/cengin_fac

Part of the Environmental Engineering Commons, Hydraulic Engineering Commons, and the Physics

Commons

Let us know how access to this document benefits you.

\section{Citation Details}

Hudson, A.S., S.A. Talke, R. Branch, C. Chickadel, G. Farquharson, and A. Jessup, 2017: Remote

Measurements of Tides and River Slope Using an Airborne Lidar Instrument. J. Atmos. Oceanic Technol., 34, 897-904, https://doi.org/10.1175/JTECH-D-16-0197.1

This Article is brought to you for free and open access. It has been accepted for inclusion in Civil and Environmental Engineering Faculty Publications and Presentations by an authorized administrator of PDXScholar. Please contact us if we can make this document more accessible: pdxscholar@pdx.edu. 


\section{Authors}

Austin S. Hudson, Stefan A. Talke, Ruth Branch, Chris Chickadel, Gordon Farquharson, and Andrew Jessup 


\title{
Remote Measurements of Tides and River Slope Using an Airborne Lidar Instrument
}

\author{
Austin S. Hudson And Stefan A. Talke \\ Civil and Environmental Engineering Department, Portland State University, Portland, Oregon \\ Ruth Branch, Chris ChickAdel, Gordon FARquharson, AND ANDREW JessuP \\ Applied Physics Laboratory, University of Washington, Seattle, Washington
}

(Manuscript received 11 October 2016, in final form 4 February 2017)

\begin{abstract}
Tides and river slope are fundamental characteristics of estuaries, but they are usually undersampled due to deficiencies in the spatial coverage of water level measurements. This study aims to address this issue by investigating the use of airborne lidar measurements to study tidal statistics and river slope in the Columbia River estuary. Eight plane transects over a 12-h period yield at least eight independent measurements of water level at $2.5-\mathrm{km}$ increments over a $65-\mathrm{km}$ stretch of the estuary. These data are fit to a sinusoidal curve and the results are compared to seven in situ gauges. In situ- and lidar-based tide curves agree to within a root-mean-square error of $0.21 \mathrm{~m}$, and the lidar-based river slope estimate of $1.8 \times 10^{-5}$ agrees well with the in situ-based estimate of $1.4 \times 10^{-5}\left(4 \mathrm{~mm} \mathrm{~km}^{-1}\right.$ difference). Lidar-based amplitude and phase estimates are within $10 \%$ and $8^{\circ}$, respectively, of their in situ counterparts throughout most of the estuary. Error analysis suggests that increased measurement accuracy and more transects are required to reduce the errors in estimates of tidal amplitude and phase. However, the results validate the use of airborne remote sensing to measure tides and suggest this approach can be used to systematically study water levels at a spatial density not possible with in situ gauges.
\end{abstract}

\section{Introduction}

The derivatives of water level in time and space $(d \zeta / d t$ and $d H / d x$, respectively) are fundamental variables in the shallow-water equations and help govern river flow, tidal currents, estuary circulation, and transport. However, surprisingly little effort has been made to remotely sense these quantities over tidal time scales in estuaries and tidal rivers, despite the greater spatial coverage that remote sensing approaches offer over traditional methods. While satellite-based altimetry currently lacks both the temporal and spatial resolution to measure estuarine water levels, more localized remote sensing efforts have focused on measuring instantaneous patterns (Pan et al. 2007), flow velocity (Harlan et al. 2010; Farquharson et al. 2014), turbulence properties (Chickadel et al. 2011; Talke et al. 2013), the statistics of short-period wave fields (Díaz Méndez et al. 2015), or bathymetry (Holman et al. 2013; Díaz Méndez et al. 2015). Since advances in technology have made the

Corresponding author e-mail: Austin S. Hudson, hudsona@ pdx.edu remote sensing of water levels over a tidal period possible, an opportunity exists to exploit readily available tools and to explore new applications.

Tides and river flow fundamentally shape estuarine hydrodynamics and morphology while at the same time are greatly affected by the underlying topography. The surface slope induced by the river flow drives water out of an estuary toward the sea, but is continually modified by wind, tides, and the dynamic reaction of water level due to flow conditions (such as a cross-channel slope due to the centripetal acceleration of the flow around a bend). The tidal wave, in particular, reacts to the bathymetry and dynamic conditions, such that, for example, landward depth/width convergence amplifies tidal amplitudes (Jay 1991) or an increase in river flow can lead to a decrease in tidal range (Moftakhari et al. 2013).

Since the spatial variation of tidal amplitude in an estuary depends on depth, landward width convergence, and friction (Friedrichs and Aubrey 1988; Jay 1991), remote sensing measurements can potentially be used to understand system properties and constrain and calibrate models. In an idealized, funnel-shaped coastal plain estuary, phase propagation primarily depends on depth but 


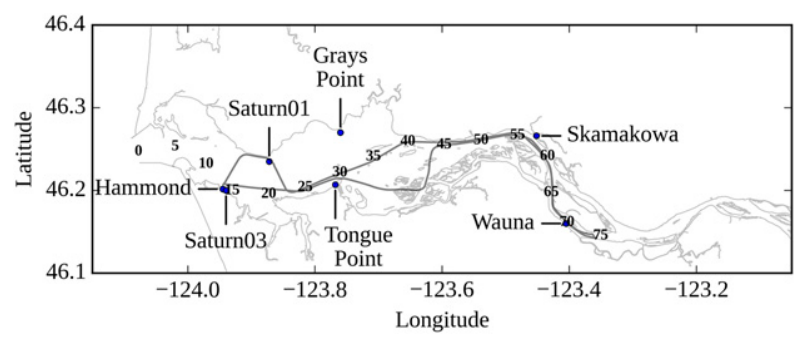

FIG. 1. CRE map with station locations (blue) and flight trajectory (black). Numbers indicate river kilometers along the main navigation channel.

is modified slightly by friction. In a more realistic estuary, however, sudden changes in depth (e.g., a sill) or width (e.g., due to a headland) can lead to partial reflections in the tide wave (Jay 1991), modifying the phase progression and leading to a complex pattern of phases and phase shifts in an estuary. In the extreme, an infinite phase propagation speed suggests standing wave resonance. While such spatial variability in phase can be modeled numerically, the typical estuary has only a few tide gauges and cannot validate such smallscale variability. Similarly, the complex hydraulics that can occur in a network of wetland channels is typically not validated with measurements. For such reasons, developing a method to remotely measure the tides may provide new tools for assessing complexity and small-scale variability, with applications for validating models, understanding transport, and potentially even measuring changes in bathymetry. Remote sensing of tides could be particularly advantageous in locations that are difficult to access or measure.

In this study, we investigate whether airplane-based lidar can be used to measure tidal properties and water level slope in estuaries. Lidar instruments estimate surface elevation by measuring the distance traveled by a laser pulse from the sensor to a target surface (Lefsky et al. 2002). Measurements are virtually instantaneous and when combined with an accurate global positioning system (GPS) can be used to define the elevation of a reflective surface relative to the earth's geoid. Lidar has been successfully used to define coastal and floodplain topography (Vrbancich et al. 2011), to estimate spectral wave characteristics (Hwang et al. 2000a,b), to detect internal waves (Magalhaes et al. 2013), to characterize flow over a sill (Marmorino et al. 2015), and even to monitor ship wakes (Reineman et al. 2009). However, to date, lidar has not been used to study tides or river slope in an estuary.

In this contribution, we use a specially equipped airplane and a "flight of opportunity" to make lidar-based measurements of the water surface of the Columbia River estuary (CRE; Fig. 1). To investigate proof of concept, a transect of approximately $65 \mathrm{~km}$ in length was flown eight times during a period of $12 \mathrm{~h}$, which included flood and ebb tide conditions. We then characterize tidal statistics and compare the results to four tide gauges of the National Oceanic and Atmospheric Administration (NOAA) and several other local gauges. Results confirm that airborne-based sensors can measure tides over a wide spatial extent of an estuary and provide an accurate estimate of water surface slope. Analysis also points to several issues that could be overcome with further research and refinement of techniques.

\section{Study area}

Located along the border of Washington and Oregon, the CRE is a mesotidal system with mixed diurnal/ semidiurnal tides and significant river discharge (annual mean of $7110 \mathrm{~m}^{3} \mathrm{~s}^{-1}$, annual minimum and maximum of $\sim 2000$ and $\sim 10600 \mathrm{~m}^{3} \mathrm{~s}^{-1}$, respectively; Naik and Jay 2011). The tidal range is largest during low-flow summer months and increases over the first 30 river kilometers ( $\mathrm{Rkm}$ ) of the estuary (on average $\sim 2.6 \mathrm{~m}$ at $\mathrm{Rkm} 30$ ), and then decreases monotonically and nearly vanishes at the head of tides at Rkm 245 (Jay et al. 2011). The principal lunar semidiurnal $\mathrm{M}_{2}$ constituent is dominant in the CRE; the amplitude at Tongue Point ( $\mathrm{Rkm} 29)$ is $\sim 1 \mathrm{~m}$, roughly 2.5 times larger than the next largest constituent, the diurnal $\mathrm{K}_{1}$ constituent (Jay et al. 1990). The $\mathrm{M}_{2}$ phase progresses along the river by approximately $1^{\circ} \mathrm{km}^{-1}$ (Giese and Jay 1989). These hydrodynamic characteristics, along with coastal upwelling (summer months) and downwelling (winter months), prominent neap-spring variations, and spatially variable channel geometry, generate large spatial gradients in water levels in the CRE.

The river slope is substantial; the Columbia River datum (CRD), defined in 1911 (Hickson 1912), suggests a fluvial slope of $\sim 1 \times 10^{-5}$ upstream of $\sim \mathrm{Rkm}$ 30 during low-flow conditions and an estuarine slope of $\sim 3 \times 10^{-6}$ in the lower $30 \mathrm{~km}$. Hence, CRD in Vancouver, Washington (Rkm 178), is roughly $1.75 \mathrm{~m}$ higher than sea level. Over time, however, anthropogenic changes to channel morphology have decreased the fluvial slope (Jay et al. 2011). In addition, plate tectonics have led to a differential uplift of $0-0.4$ m century $^{-1}$, particularly in the lower $30 \mathrm{~km}$ (Burgette et al. 2009). Landslides and wetland subsidence may have also lead to local instabilities in benchmarks. Given these factors, significant uncertainty exists in local CRD, river slope, and the tide gauge datums (NOAA 2015). In some locations, CRD may even vary by $0.1-0.15 \mathrm{~m}$ between the Oregon and Washington sides of the river (E. Burnette 2014, personal discussion). As we show later, this 
TABLE 1. RMSE comparison of in situ and lidar data (statistics in meters). Average RMSE among lidar and in situ measurements is $0.41 \mathrm{~m}$ and among harmonic analysis predictions is $0.21 \mathrm{~m}$. Average bias of lidar data is $0.48 \mathrm{~m}$. Bias is only reported at stations referenced to a datum.

\begin{tabular}{|c|c|c|c|c|}
\hline Station & Sample size & Pointwise error [ $95 \%$ confidence interval] & $\begin{array}{l}\text { Harmonic analysis error } \\
{[95 \% \text { confidence interval }]}\end{array}$ & Bias \\
\hline Hammond & 10 & $0.31[0.22,0.57]$ & $0.07[0.07,0.09]$ & 0.38 \\
\hline Saturn03 & 12 & $0.38[0.27,0.64]$ & $0.08[0.08,0.10]$ & - \\
\hline Saturn01 & 13 & $0.37[0.26,0.60]$ & $0.14[0.14,0.18]$ & - \\
\hline Tongue Point & 14 & $0.35[0.25,0.56]$ & $0.07[0.07,0.09]$ & 0.50 \\
\hline Grays Point & 7 & $0.36[0.23,0.78]$ & $0.04[0.04,0.04]$ & - \\
\hline Skamokawa & 8 & $0.58[0.39,1.19]$ & $0.41[0.37,0.45]$ & 0.46 \\
\hline Wauna & 8 & $0.52[0.34,1.05]$ & $0.34[0.33,0.43]$ & 0.59 \\
\hline All stations & 72 & $0.41[0.34,0.50]$ & $0.21[0.20,0.22]$ & 0.48 \\
\hline
\end{tabular}

uncertainty is one of the factors impacting our ability to confirm river slope estimates using lidar.

\section{Methods}

Point (1D) data of relative elevation were collected at $3 \mathrm{kHz}$ using a Riegl LD90-3800EHS-FLP lidar instrument, which was mounted to the side of a Cessna 172SP. Other instrumentation included a red-greenblue (RGB) video camera (the Point Gray Chameleon) and a longwave infrared camera (the DRS UC640). A real-time kinematic (RTK) GPS was mounted near the lidar instrument and measured airplane position and elevation above the World Geodetic System 1984 (WGS84)'s Earth Gravitational Model 1996 (EGM96) geoid. An inertial motion unit (IMU) measured pitch, roll, and yaw at $5 \mathrm{~Hz}$.

Lidar data were collected during eight flights over a 12-h period on 11 June 2013 between Rkm 10 and 75 . Flight conditions were generally calm; however, lateral wind and turbulence occurred over the ridge between $\mathrm{Rkm} 50$ and 75 and may have impacted some measurements (especially when GPS and lidar instruments were not perfectly synchronized; see below). During the experiment the greater diurnal tidal range measured at Tongue Point (Fig. 1) was $\sim 2.5 \mathrm{~m}$ and the mean daily discharge was $\sim 7500 \mathrm{~m}^{3} \mathrm{~s}^{-1}$, or roughly average conditions. Flight paths were flown at an elevation of $\sim 350$ $450 \mathrm{~m}$ and followed a looping pattern that (i) ensured measurements in both the north and south channels of the estuary and (ii) coincided with seven in situ water level gauges (blue circles, Fig. 1).

Tide data from gauges at Hammond ( $\mathrm{Rkm}$ 13.5), Tongue Point (Rkm 29), Skamokawa (Rkm 57), and Wauna (Rkm 70) were obtained from NOAA. Additional water level data from the Saturn01 (Rkm 20), Saturn03 (Rkm 14.5), and Grays Point (Rkm 31) were obtained from the Center for Coastal Margin Observation and Prediction (CMOP; http://www.stccmop.org/).
NOAA tide data were referenced to the WGS84 EGM96 geoid using the NOAA Vertical Datum Transformation (VDatum) program. Since CMOP data do not have a reference datum, their 11 June averages were shifted to those of the nearest NOAA gauge.

Water levels relative to the WGS84 EGM96 geoid were derived from lidar data by subtracting lidar measurements from the plane elevation, as measured by the GPS. Variability in the lidar pathlength caused by airplane pitch, roll, and vertical movement was geometrically corrected to obtain a vertical measurement. Manual inspection was then used to remove time periods in which the flight path crossed land or wetland areas. When estimating tidal properties from the data [see Eq. (3)], an unexplained, persistent bias of $0.48 \mathrm{~m}$ was initially observed in the lidar data relative to the NOAA tide data (Table 1); to enable comparison, we removed this bias from the lidar data.

A clock drift of several seconds per transect was observed in the lidar data during postprocessing. To minimize errors in estimated water levels introduced by discrepancies in GPS and lidar time stamps, lidar time series were shifted to match the GPS data by use of a Taylor's series expansion (an approach inspired by quality assurance methods for tide data; cf. Agnew 1986; Miguez et al. 2008). Taylor's theorem relates a function with its derivatives, which for the GPS elevations takes the following form:

$$
h_{\mathrm{GPS}}(t+\Delta t)=h_{\mathrm{GPS}}(t)+\frac{d h_{\mathrm{GPS}}(t)}{d t} \Delta t,
$$

where $h_{\mathrm{GPS}}$ is the plane elevation and $\Delta t$ is some small time increment. Assuming that lidar data $h_{\text {lidar }}$ lead $h_{\mathrm{GPS}}$ by a constant $\Delta t(<2-3 \mathrm{~s})$ over a small measurement time period (e.g., 10 or $30 \mathrm{~s}$ of data) implies that $h_{\text {lidar }}=$ $h_{\mathrm{GPS}}(t+\Delta t)$, or

$$
h_{\mathrm{LIDAR}}(t)-h_{\mathrm{GPS}}(t)=\frac{d h_{\mathrm{GPS}}(t)}{d t} \Delta t .
$$




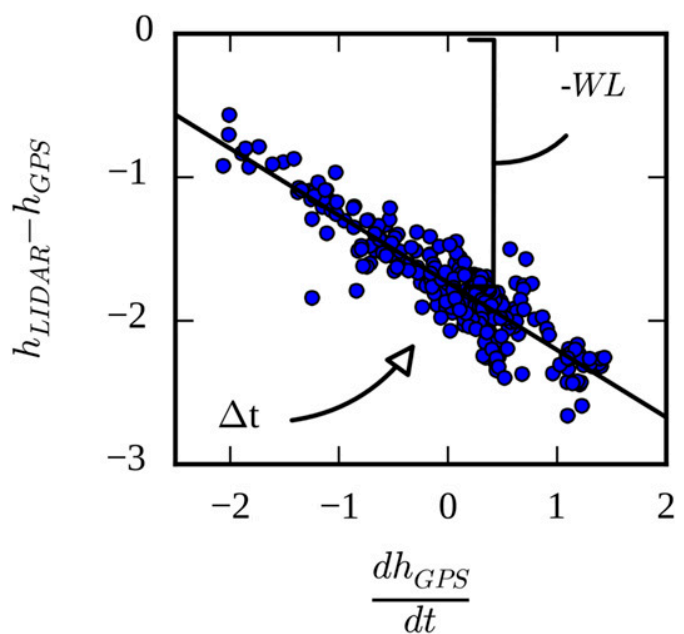

FIG. 2. Scatterplot of lidar reading minus GPS height vs GPS height derivative. Data are from a 60-s segment of the first flight. The slope estimates $\Delta t$ and the intercept approximates - WL [see Eq. (3)]. The $x$-axis unit is set in $\mathrm{m} \mathrm{s}^{-1}$. The $y$-axis unit is set in $\mathrm{m}$.

Because $h_{\text {lidar }}, h_{\mathrm{GPS}}$, and $d h_{\mathrm{GPS}}(t) / d t$ are known, $\Delta t$ can be estimated in an ordinary least squares sense (Fig. 2). Here, the estimated slope represents the time lag and the intercept approximates the height difference between GPS elevation and lidar measurements (Fig. 2).

Since the time lag of the lidar data was not constant throughout each flight, lidar water levels were estimated by recursively applying the approach mentioned above to subsections of each transect. Subsections were defined as 10-, 30-, and 60-s segments, and the results from the three trials were averaged to obtain the quantity $h_{\mathrm{LIDAR}}-h_{\mathrm{GPS}}\left(\right.$ water level $\left.=h_{\mathrm{GPS}}-h_{\mathrm{LIDAR}}\right)$ at each location along the flight path. Note that this averaging essentially acts as a low-pass filter to produce lidar-based water levels at $1 \mathrm{~Hz}$.

Lidar-based water levels were next validated using pointwise comparisons with in situ measurements. Only lidar measurements within $2.5 \mathrm{~km}$ of the in situ gauges were considered, but a larger radius of $6 \mathrm{~km}$ was used for the Saturn01 and Grays Point gauges, due to their distance from the flight path and a paucity of points, and may impact comparisons. Note that the time difference between in situ and lidar measurements never exceeded $3 \mathrm{~min}$.

Tidal properties were estimated by fitting the following semidiurnal sinusoidal curve to the set of lidar elevations at each location,

$$
\mathrm{WL}=H+A \cos \left(\frac{2 \pi t}{T}-\phi\right)
$$

where $\varphi$ is the tidal phase, $T$ is the period of the tidal wave, $t$ is time, $H$ is the residual (approximately tidally averaged) water level relative to the geoid, and $A$ is the tidal amplitude. The time period $T$ was approximated to be $12.42 \mathrm{~h}$, corresponding to the dominant $\mathrm{M}_{2}$ tidal frequency. For comparison, concurrent measurements at in situ gauges were also analyzed over the experiment time period using Eq. (3). Further tidal constituents were neglected because both the sampling frequency and the experiment duration were too small to yield accurate estimates for more than one wave.

\section{Results}

Overall, measurements validate the idea that airborne lidar can be used to approximate tidal properties and water level slope. Pointwise comparisons between lidar and in situ data demonstrate that lidar estimates follow the tidal undulations at each station (Fig. 3) with an average root-mean-square-error (RMSE) of $0.41 \mathrm{~m}$ among the stations (Table 1). Fitting a harmonic curve [Eq. (3)] to the data significantly improves the overall comparison, and results in an RMSE between in situ and lidar curves of $0.21 \mathrm{~m}$. The largest errors are observed at Skamokawa, Washington, and Wauna, Oregon (Table 1; Figs. 3f,g) -wind-affected locations that contained few independent measurements over the study period because they were near the airplane turnaround point (eight independent points). Nevertheless, the in situ measurements and tide curves are within the $95 \%$ confidence interval of lidar-based curves (Fig. 3).

The along-channel (2.5-km resolution) spatial variation of lidar-based tidal statistics approximates in situ variation (Fig. 4). After a small bias correction (see section 3), tidally averaged (residual) water levels $[H$ obtained from Eq. (3)] agree to within an RMS error of $0.03 \mathrm{~m}$ with in situ results (Fig. 4a). The lidar-based river slope, estimated by fitting a line to residual water levels, closely reproduces the slope expected from both the local CRD datum and NOAA tide gauges. The lidarbased estimate of $1.8 \times 10^{-5}$ is $30 \%$ greater than the in situ-based estimate of $1.4 \times 10^{-5}\left(4 \mathrm{~mm} \mathrm{~km}^{-1}\right.$ difference) but is not statistically different at the $95 \%$ confidence level. Residual water levels derived from lidar data further reveal a change in river slope at about $\mathrm{Rkm} 40$ that is difficult to deduce from the sparsely sampled in situ data, but it seems plausible, since the river width more than doubles seaward of this location. The CRD based on 1911 measurements (Hickson 1912) shows a similar inflection at around the same location. Seaward of Rkm 40 the lidar-based river slope is $5.3 \times 10^{-6}$ and landward the river slope is $2.8 \times 10^{-5}$.

Predicted tidal amplitudes and phases from lidar data are within $46 \%$ and $27^{\circ}$, respectively, of in situ measurements (Table 2). Lidar and in situ measurements agree better in the first $30 \mathrm{Rkm}$ of the estuary (amplitudes 

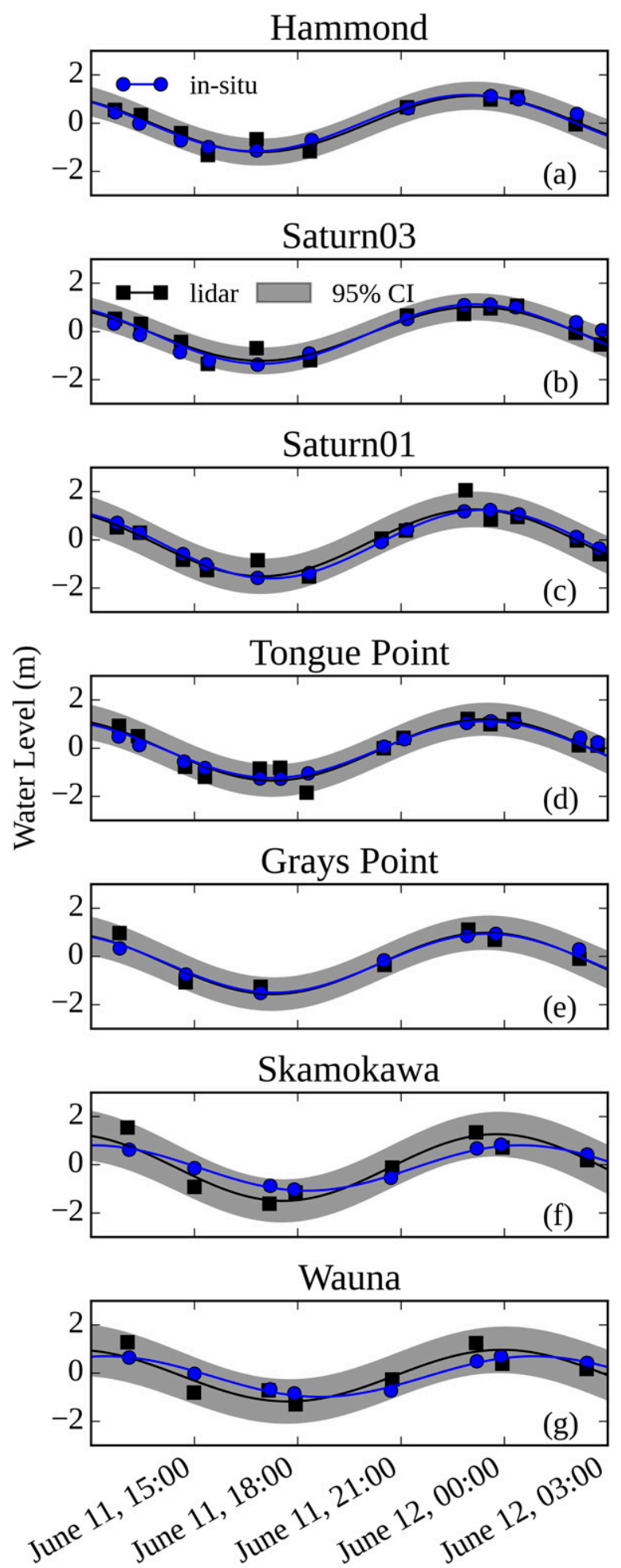

FIG. 3. Lidar (black squares) and in situ (blue circles) data at each station. Lidar data follow tidal movements of the water surface with noticeable scatter. Any difference in residual water level [the $H$ term in Eq. (1)] has been removed before comparison. Harmonic model of lidar (black lines) and in situ (blue lines) data is also given for each station. All times are in UTC. within $10 \%$ and phases within $8^{\circ}$ ), where there were better flight conditions (thus smaller measurement error; see section 3) and more data. Both in situ- and lidar-based estimates show an increase in tidal amplitudes between $\mathrm{Rkm} 10$ and 25. A rapid decrease is observed near Rkm 25 in both datasets, and thereafter amplitudes increase toward $\mathrm{Rkm}$ 40. The increasing tidal amplitude up to $\mathrm{Rkm} 25$ and the step function decrease around $\mathrm{Rkm} 25$ point to a partial reflection of the tide wave; while partial reflections near Tongue Point (around Rkm 30) have been discussed before (Jay 1984; Giese and Jay 1989), in situ data coverage is too sparse to confirm our observations. Measured patterns of tidal amplitude show little change between $\mathrm{Rkm} 40$ and 60 and then further decay landward of $\mathrm{Rkm}$ 60, but lidar-based amplitudes are consistently biased above in situ-based amplitudes (Fig. 4b).

Lidar data well reproduce in situ-based phase variability in the lower $30 \mathrm{~km}$ of the estuary (Fig. 4c), with a phase difference of $<5^{\circ}$ in four out of five gauges (Table 2). Upstream phase estimates at Rkm 57 and 70 show substantially greater differences of $\sim 20^{\circ}-27^{\circ}$. Since in situ measurements lack spatial coverage, it is unclear at what point between $\mathrm{Rkm} 30$ and 57 the lidar estimates diverge from actual tide progression. Nonetheless, the in situ phase progression of $54.6^{\circ}$ between $\mathrm{Rkm} 13.5$ and 70 is more consistent with previous investigations (Giese and Jay 1989).

Note that although lidar and in situ tidal statistics diverge upstream near Wauna and Skamokawa, the estimates are not statistically different (Table 2; Figs. 4b,c). Moreover, analysis shows that the inaccuracies in the lidar estimates are primarily due to the paucity of data used in Eq. (3) rather than a deficiency in the method. Approximately 20 measurements would be necessary to drive phase and amplitude errors down to an acceptable $10 \%$ (see the next section).

\section{Discussion and conclusions}

Results show proof of concept that lidar-based measurements of tides are possible, but they point to areas where improvements in experiment design and measurement accuracy are necessary before application to address scientific or operational questions. In particular, the RMSEs observed in the experiment were larger than the reported GPS accuracy of $10 \mathrm{~cm}$ and the lidar resolution of $6.5 \mathrm{~cm}$. Reasons may include the slight time drift between the lidar and GPS instrumentation, and the occasionally windy conditions during the experiment, which produced short-time-scale variations in airplane elevation. Moreover, water is known to be a relatively opaque surface at the $0.9-\mu \mathrm{m}$ laser wavelength 

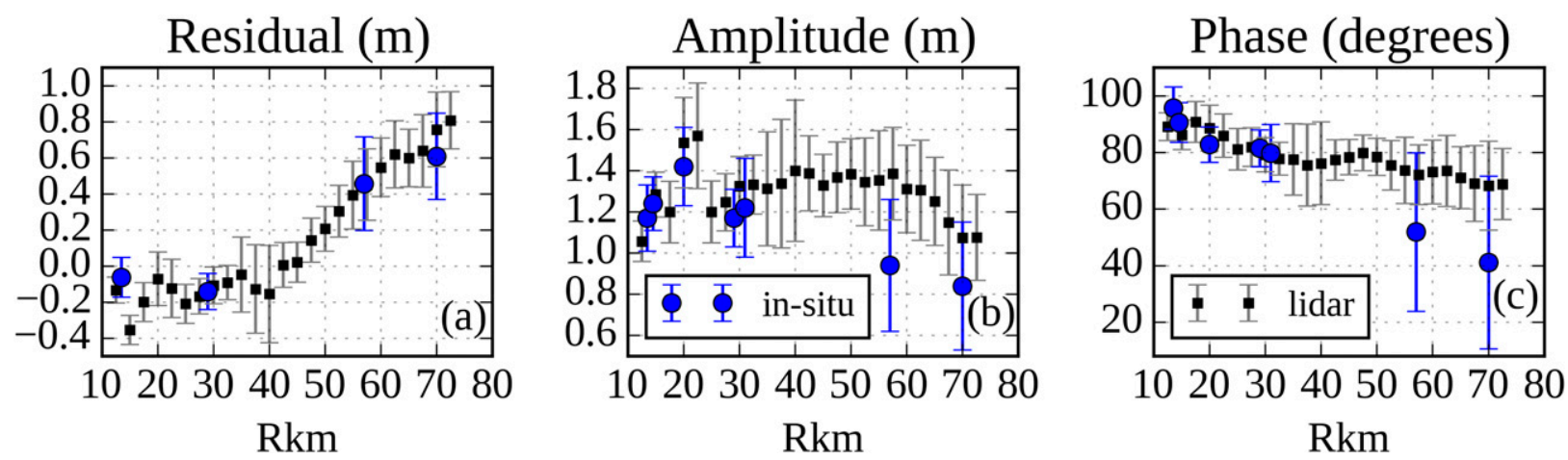

FIG. 4. Lidar (black squares) and in situ (blue circles) estimates of residual water level, tidal amplitude, and phase. Lidar-based residual water levels are biased above in situ water levels, so $0.48 \mathrm{~m}$ was added to in situ water levels to facilitate slope comparisons. Lidar-based phases and amplitudes agree with in situ estimates throughout most of the estuary but are larger near Sakmokawa and Wauna.

of the lidar (Buiteveld et al. 1994), so water level measurements include high-frequency wind waves (Hwang et al. 2000a,b; Reineman et al. 2009; Vrbancich et al. 2011), which may also introduce noise.

Given noisy measurements, the method of fitting a sinusoidal curve to the lidar and in situ data successfully improves estimates of water level, and results in statistically similar tidal amplitude and phase (Table 2; Figs. 3, 4). Increasing the frequency of measurements, however, would further reduce amplitude and phase errors, since random error is proportional to the square root of the sample size. For example, given 10 data points, an amplitude of $1 \mathrm{~m}$, and an RMSE of $0.3 \mathrm{~m}$, a Monte Carlo-type experiment with 10000 realizations of Eq. (3) produced an average phase error of $\sim 10^{\circ}$ and an amplitude error of $\sim 0.15 \mathrm{~m}$. Doubling the number of data points to 20 decreases the phase error to $\sim 6^{\circ}$ and the amplitude error to $0.10 \mathrm{~m}$. Similarly, reducing the RMSE of the simulated dataset to the manufacturer value of $0.1 \mathrm{~m}$ also reduces the amplitude and phase errors-improving the results to within $3^{\circ}$ and $0.05 \mathrm{~m}$ with 10 data points, respectively. Hence, a combination of undersampling and sampling error helps explain why lidar-based amplitude, phase, and (to some extent) slope measurements only approximately agree with in situ measurements. Note that a longer period is also necessary to resolve other tidal constituents, overtides, the spring-neap cycle, and other features of the system (Foreman 1977; Jay and Flinchem 1999).

The 0.48-m bias of lidar measurements and slope estimate errors reported above may point to possible issues in our geometric corrections, or with the vertical datum used in reducing the measurements. As discussed earlier, vertical uplift and other geologic factors may influence the accuracy of the station datum used in gauges along the CRE, and therefore its connection with other vertical datum and geoids. Indeed, uncertainties of
$O(1)$ m accompany datum conversions between the CRE tide gauge network and the WGS84 EGM96 geoid (NOAA 2015). Moreover, errors in the geoid slope are thought to vary from about 2 to $5 \mathrm{~mm} \mathrm{~km}^{-1}$ along the Pacific Northwest (Pavlis et al. 2012), and local estimates of the geoid are still being refined, such that successive geoid versions exhibit bias and result in different river slope estimates. For example, when compared to WGS84 EGM96, the lidar-based river slope referenced to WGS84 EGM84 is about $70 \%$ larger, whereas the slope referenced to WGS84 EGM2008 is $8 \%$ less $\left(3.1 \times 10^{-5}\right.$ and $1.7 \times 10^{-7}$, respectively). In addition, WGS84 EGM84 is biased $1.0 \mathrm{~m}$ below, and WGS84 EGM2008 is biased $0.45 \mathrm{~m}$ above WGS84 EGM96. Hence, it is not improbable that geoid errors affect our comparison with in situ measurements. An interesting conclusion of our experiment is that the water level slope in the Columbia River is not exactly known, though the relative consistency between lidar and in situ data is encouraging.

Initial results suggest that improvements in experimental methodology and possibly geoid estimates are required before the many scientific questions surrounding spatially refined tide measurements can be fully addressed. The spatial variation in surface tides and water

TABLE 2. Comparison of $\mathrm{D}_{2}$ amplitude $(\mathrm{m})$ and phases $\left(^{\circ}\right)$ estimated from lidar and in situ data.

\begin{tabular}{lccccc}
\hline \hline & \multicolumn{2}{c}{ Amplitude $(\mathrm{m})[$ std dev $]$} & & \multicolumn{2}{c}{ Phase $\left({ }^{\circ}\right)$ [std dev] } \\
\cline { 2 - 3 } \cline { 5 - 6 } Station $(\mathrm{Rkm})$ & In situ & Lidar & & In situ & Lidar \\
\hline Hammond (13.5) & $1.17[0.15]$ & $1.17[0.15]$ & & $95.7[7.12]$ & $91.1[6.98]$ \\
Saturn03 (14.5) & $1.24[0.13]$ & $1.12[0.13]$ & & $90.6[6.16]$ & $90.2[7.71]$ \\
Saturn01 (20) & $1.42[0.17]$ & $1.39[0.17]$ & & $82.8[6.71]$ & $90.3[6.14]$ \\
Tongue Point (29) & $1.17[0.14]$ & $1.27[0.14]$ & & $81.5[6.69]$ & $80.7[6.32]$ \\
Grays Point (31) & $1.22[0.22]$ & $1.27[0.23]$ & $79.8[10.5]$ & $80.6[9.85]$ \\
Skamokawa (57) & $0.94[0.36]$ & $1.38[0.23]$ & & $51.9[26.6]$ & $72.1[10.9]$ \\
Wauna (70) & $0.84[0.30]$ & $1.07[0.25]$ & & $41.1[30.9]$ & $67.7[14.8]$ \\
\hline
\end{tabular}


levels results from numerous processes, including friction, stratification, and underlying bathymetry; therefore, provided with sufficient information and appropriate models, future research might be able to study overtide generation, mixing and transport, and time-changing stratification (Jay and Smith 1990; Jay and Musiak 1994, 1996; Cheng et al. 2013; Burchard et al. 2013). Of particular interest would be to use $2 \mathrm{D}$ scanning instruments that measure a swath in bathymetrically variable areas. Dual-frequency lidar measurements could also be used in shallow (optically clear) water to obtain a relative height measurement by simultaneously measuring water level and bottom topography without needing a confident datum estimate.

Historically, tide analysis in estuaries has primarily focused on analyzing gauge data in a fixed Eulerian reference frame that is temporally rich (typically hourly data) but spatially poor (typically between 2 and 10 gauges in major U.S. estuaries). However, satellitebased instruments will soon provide spatially resolved, but temporally poor, measurements of estuary and river tides. For example, the Surface Water Ocean Topography (SWOT) mission (scheduled for launch in 2020) will provide high-accuracy estimates of water level and water level slope $\left(0.1 \mathrm{~m}\right.$ and $0.01 \mathrm{~m} \mathrm{~km}^{-1}$, respectively $)$ with a spatial resolution of $50 \mathrm{~m}$ (Neeck et al. 2012). To interpret such measurements, however, the contribution of the tide and the tidally averaged water level slope to the instantaneous remote measurement needs to be separated. Since the existing tide gauge network is spatially sparse, quasi-synoptic remote sensing measurements such as the lidar-based measurements described herein may potentially be useful for interpreting and understanding the instantaneous spatial shape of a tide curve in estuaries.

Acknowledgments. Office of Naval Research Grants N00014-13-1-0084 and N00014-10-1-0932 and National Science Foundation Award 1455350 helped fund this research. We thank Ed Zaron for his helpful discussions on geoid modeling and errors.

\section{REFERENCES}

Agnew, D. C., 1986: Detailed analysis of tide gauge data: A case history. Mar. Geod., 10, 231-255, doi:10.1080/01490418609388024.

Buiteveld, H., J. H. M. Hakvoort, and M. Donze, 1994: The optical properties of pure water. Ocean Optics XII, J. S. Jaffe, Ed., International Society for Optical Engineering (SPIE Proceedings, Vol. 2258), 174-183, doi:10.1117/12.190060.

Burchard, H., H. M. Schuttelaars, and W. R. Geyer, 2013: Residual sediment fluxes in weakly-to-periodically stratified estuaries and tidal inlets. J. Phys. Oceanogr., 43, 1841-1861, doi:10.1175/ JPO-D-12-0231.1.

Burgette, R. J., R. J. Weldon, and D. A. Schmidt, 2009: Interseismic uplift rates for western Oregon and along-strike variation in locking on the Cascadia subduction zone. J. Geophys. Res. Solid Earth, 114, doi:10.1029/2008JB005679.

Cheng, P., H. E. de Swart, and A. Valle-Levinson, 2013: Role of asymmetric tidal mixing in the subtidal dynamics of narrow estuaries. J. Geophys. Res. Oceans, 118, 2623-2639, doi:10.1002/ jgrc.20189.

Chickadel, C. C., S. A. Talke, A. R. Horner-Devine, and A. T. Jessup, 2011: Infrared-based measurements of velocity, turbulent kinetic energy, and dissipation at the water surface in a tidal river. IEEE Geosci. Remote Sens. Lett., 8, 849-853, doi:10.1109/LGRS.2011.2125942.

Díaz Méndez, G. M., M. C. Haller, B. Raubenheimer, S. Elgar, and D. A. Honegger, 2015: Radar remote sensing estimates of waves and wave forcing at a tidal inlet. J. Atmos. Oceanic Technol., 32, 842-854, doi:10.1175/JTECH-D-14-00215.1.

Farquharson, G., H. Deng, Y. Goncharenko, and J. Mower, 2014: Dual-beam ATI SAR measurements of surface currents in the nearshore ocean. 2014 IEEE Geoscience and Remote Sensing Symposium: Proceedings, IEEE, 2661-2664, doi:10.1109/ IGARSS.2014.6947021.

Foreman, M. G. G., 1977: Manual for Tidal Heights Analysis and Prediction. Institute of Ocean Sciences Marine Science Rep. 77-10, $97 \mathrm{pp}$.

Friedrichs, C. T., and D. G. Aubrey, 1988: Non-linear tidal distortion in shallow well-mixed estuaries: A synthesis. Estuarine Coastal Shelf Sci., 27, 521-545, doi:10.1016/0272-7714(88)90082-0.

Giese, B. J., and D. A. Jay, 1989: Modelling tidal energetics of the Columbia River Estuary. Estuarine Coastal Shelf Sci., 29, 549_ 571, doi:10.1016/0272-7714(89)90010-3.

Harlan, J., E. Terrill, L. Hazard, C. Keen, D. Barrick, C. Whelan, S. Howden, and J. Kohut, 2010: The Integrated Ocean Observing System high-frequency radar network: Status and local, regional, and national applications. Mar. Technol. Soc. J., 44, 122-132, doi:10.4031/MTSJ.44.6.6.

Hickson, R. E., 1912: A report on the establishment of river gauges on lower Columbia River \& Willamette Rivers. Army Corps of Engineers, 8 pp.

Holman, R., N. Plant, and T. Holland, 2013: cBathy: A robust algorithm for estimating nearshore bathymetry. J. Geophys. Res. Oceans, 118, 2595-2609, doi:10.1002/jgrc.20199.

Hwang, P. A., D. W. Wang, E. J. Walsh, W. B. Krabil, and R. N. Swift, 2000a: Airborne measurements of the wavenumber spectra of ocean surface waves. Part I: Spectral slope and dimensionless spectral coefficient. J. Phys. Oceanogr., 30, 2753-2767, doi:10.1175/1520-0485(2001)031<2753:AMOTWS >2.0.CO;2.

,,,,---- and,$- 2000 \mathrm{~b}$ : Airborne measurements of the wavenumber spectra of ocean surface waves. Part II: Directional distribution. J. Phys. Oceanogr., 30, 2768-2787, doi:10.1175/1520-0485(2001)031<2768:AMOTWS>2.0.CO;2.

Jay, D. A., 1984: Circulatory processes in the Columbia River estuary. CREST Rep., 169 pp.

, 1991: Green's law revisited: Tidal long-wave propagation in channels with strong topography. J. Geophys. Res., 96, 20 58520 598, doi:10.1029/91JC01633.

_ , and J. D. Smith, 1990: Circulation, density distribution and neap-spring transitions in the Columbia River Estuary. Prog. Oceanogr., 25, 81-112, doi:10.1016/0079-6611(90)90004-L.

, and J. D. Musiak, 1994: Particle trapping in estuarine tidal flows. J. Geophys. Res., 99, 20 445-20 461, doi:10.1029/94JC00971.

- and - 1996: Internal tidal asymmetry in channel flows: Origins and consequences. Mixing in Estuaries and Coastal Seas, C. Pattiaratchi, Ed., Coastal and Estuarine Studies, Vol. 50, Amer. Geophys. Union, 211-249, doi:10.1029/CE050p0211. 
and E. P. Flinchem, 1999: A comparison of methods for analysis of tidal records containing multi-scale non-tidal background energy. Cont. Shelf Res., 19, 1695-1732, doi:10.1016/ S0278-4343(99)00036-9.

— B. S. Giese, and C. R. Sherwood, 1990: Energetics and sedimentary processes in the Columbia River Estuary. Prog. Oceanogr., 25, 157-174, doi:10.1016/0079-6611(90)90006-N.

- K. Leffler, and S. Degens, 2011: Long-term evolution of Columbia River tides. J. Waterw. Port Coastal Ocean Eng., 137, 182-191, doi:10.1061/(ASCE)WW.1943-5460.0000082.

Lefsky, M. A., W. B. Cohen, G. G. Parker, and D. J. Harding, 2002: Lidar remote sensing for ecosystem studies. BioScience, 52, 1930, doi:10.1641/0006-3568(2002)052[0019:LRSFES]2.0.CO;2.

Magalhaes, J. M., J. C. Silva, M. Batista, L. Gostiaux, T. Gerkema, A. L. New, and D. R. G. Jeans, 2013: On the detectability of internal waves by imaging lidar. Geophys. Res. Lett., 40, 34293434, doi:10.1002/grl.50669.

Marmorino, G., J. Brozena, G. G. Smith, R. Liang, M. Vermillion, and W. D. Miller, 2015: Lidar-measured Bernoulli response to tidal flow over a sill. IEEE Geosci. Remote Sens. Lett., 12, 1116-1120, doi:10.1109/LGRS.2014.2385599.

Miguez, B. M., L. Testut, and G. Wöppelmann, 2008: The Van de Casteele test revisited: An efficient approach to tide gauge error characterization. J. Atmos. Oceanic Technol., 25, 12381244, doi:10.1175/2007JTECHO554.1.

Moftakhari, H. R., D. A. Jay, S. A. Talke, T. Kukulka, and P. D. Bromirski, 2013: A novel approach to flow estimation in tidal rivers. Water Resour. Res., 49, 4817-4832, doi:10.1002/ wrcr.20363.

Naik, P. K., and D. A. Jay, 2011: Distinguishing human and climate influences on the Columbia River: Changes in mean flow and sediment transport. J. Hydrol., 404, 259-277, doi:10.1016/ j.jhydrol.2011.04.035.

Neeck, S. P., E. J. Lindstrom, P. V. Vaze, and L.-L. Fu, 2012: Surface Water and Ocean Topography (SWOT) mission. Sensors, Systems, and Next-Generation Satellites XVI, R. Meynart, S. P. Neeck, and H. Shimoda, Eds., International Society for Optical Engineering (SPIE Proceedings, Vol. 8533), doi:10.1117/12.981151.

NOAA, 2015: Estimation of vertical uncertainties in VDatum. Accessed May 2016. [Available online at http://vdatum.noaa. gov/docs/est_uncertainties.html.]

Pan, J., D. A. Jay, and P. M. Orton, 2007: Analyses of internal solitary waves generated at the Columbia River plume front using SAR imagery. J. Geophys. Res., 112, doi:10.1029/ 2006JC003688.

Pavlis, N. K., S. A. Holmes, S. C. Kenyon, and J. K. Factor, 2012: The development and evaluation of the Earth Gravitational Model 2008 (EGM2008). J. Geophys. Res., 117, B04406, doi:10.1029/2011JB008916.

Reineman, B. D., L. Lenain, D. Castel, and W. K. Melville, 2009: A portable airborne scanning lidar system for ocean and coastal applications. J. Atmos. Oceanic Technol., 26, 2626-2641, doi:10.1175/2009JTECHO703.1.

Talke, S. A., A. R. Horner-Devine, C. C. Chickadel, and A. T. Jessup, 2013: Turbulent kinetic energy and coherent structures in a tidal river. J. Geophys. Res. Oceans, 118, 6965-6981, doi:10.1002/2012JC008103.

Vrbancich, J., W. Lieff, and J. Hacker, 2011: Demonstration of two portable scanning lidar systems flown at low-altitude for investigating coastal sea surface topography. Remote Sens., $\mathbf{3}$, 1983-2001, doi:10.3390/rs3091983. 